\title{
Very low penetrance in 85 Japanese families with facioscapulohumeral muscular dystrophy $1 \mathrm{~A}$
}

\author{
K Goto, I Nishino, Y K Hayashi
}

J Med Genet 2004;41:e12 (http://www.jmedgenet.com/cgi/content/full/41/1/e12)

$\mathrm{F}$ acioscapulohumeral muscular dystrophy (FSHD) is the third most common form of muscular disorder with an autosomal dominant trait, and its frequency is about one in 20 000. It is characterised by weakness and atrophy of the facial, shoulder girdle, and upper limb muscles. The pelvic girdle and lower limbs subsequently also become involved, and, eventually, $20 \%$ of patients have to use wheelchairs by the age of 40 years. ${ }^{1}$ Most patients develop clinical symptoms in late childhood or adolescence, although the onset of the disease and its clinical severity are heterogeneous.

The FSHD locus was mapped to the subtelomeric region of the long arm of chromosome 4 by genetic linkage analysis. ${ }^{2-4}$ More than $95 \%$ of patients with FSHD had a small $(<35 \mathrm{~kb})$ EcoRI fragment on chromosome $4 \mathrm{q} 35$ on southern blotting analysis with the probe pl3E-11 (FSHDIA; MIM 158900)..$^{5-8}$ This EcoRI fragment contains tandem repeats of the $3.3 \mathrm{~kb}$ $K p n I$ unit (D4Z4). The number of D4Z4 repeats varies from 11 to 150 in healthy people, although the number is fewer than 11 in patients with FSHD 1 A. ${ }^{6}{ }^{8}$ Although no responsible gene has been isolated within the FSHD region, the number of D4Z4 repeats is a critical determinant of the age of onset and clinical severity of the disease. In general, 1-3 D4Z4 repeats are associated with a severe form of the disease that presents in childhood, 4-7 repeats with the most common form of FSHD, and 8-10 repeats with a milder disease and reduced penetrance. ${ }^{8-12}$

Probe pl3E-11 crosshybridises with chromosome 10q26, which contains highly homologous $3.3 \mathrm{~kb}$ KpnI repeated units. As the $B \ln \mathrm{I}$ restriction enzyme site exists exclusively within each unit derived from 10q26, but not in D4Z4 (a unit from 4q35), double enzyme digestion with EcoRI and BlnI can discriminate between the $4 \mathrm{q} 35$ (BlnI resistant) fragments and 10q26 (BlnI sensitive) fragments. ${ }^{13}$ The highly homologous structure means that the subtelomeric interchromosomal translocation between chromosomes 4 and 10 occurs often (in about $20-30 \%$ of people) and has been suggested to contribute to deletion of KpnI repeats on chromosome $4 q 35 .{ }^{14-16}$ The frequency of translocation, however, was not significantly different between healthy people and those with FSHD. ${ }^{17}$

More complicatedly, some people have five EcoRI fragments in total, including one additional $B \ln \mathrm{I}$ resistant fragment. These people were suggested to have somatic mosaicism of the $4 \mathrm{q} 35$ region and two cell populations with different fragment sizes. ${ }^{10} 18-21$

To clarify the frequency of the de novo mutation, the penetrance, and influence of the shortened repeats on clinical symptoms, we performed clinical and genetic analyses on patients with FSHDIA and both parents of each patient.

\section{PARTICIPANTS AND METHODS}

We extracted genomic DNA from peripheral blood lymphocytes with a standard technique after informed consent was obtained. We analysed 255 DNA samples, including samples

\section{Key points}

- Facioscapulohumeral muscular dystrophy (FSHD) is a common autosomal dominant muscular dystrophy.

- Most patients with FSHD have fewer numbers of tandem repeated $3.3 \mathrm{~kb} \mathrm{Kpnl} \mathrm{units} \mathrm{on} \mathrm{chromosome}$ 4 q35 (FSHDIA), and southern blotting analysis with the probe $\mathrm{p} 13 \mathrm{E}-11$ shows a small EcoRI fragment $(<35 \mathrm{~kb})$.

- To clarify the deletion mechanism and influence of shortened repeats on clinical symptoms, we examined 85 Japanese unrelated patients with FSHDIA and both parents of each patient.

- In $35(41 \%)$ families, only the proband had a small EcoRI fragment and these were suggested to be de novo mutations. In the remaining familial cases, somatic mosaicism of the $4 \mathrm{q} 35$ region was seen in $17 /$ 50 (34\%) parents with a small EcoRI fragment. This suggests that deletion of the $4 \mathrm{q} 35$ region of the chromosome was generated often during mitosis and transmitted to the next generation.

- Although almost complete penetrance of FSHD is known, no clinical symptoms were seen in 26 (52\%) parents who carried a small EcoRI fragment (including people with mosaicism) in this study.

- The high frequency of parents without the disease but with deletion of the $4 \mathrm{q} 35$ region implies the role of additional factors in the development of the clinical symptoms of FSHD.

from 85 Japanese patients with FSHDlA and both parents of each patient.

We used pulsed field gel electrophoresis (PFGE) and conventional gel electrophoresis to determine the size and chromosomal origin (chromosome 4 or 10) of each of the fragments. The DNA was double digested with EcoRI/HindIII and EcoRI/BlnI for PFGE and with EcoRI and EcoRI/BlnI for the conventional study. After we transferred the DNA to Hybond $\mathrm{N}^{+}$(Amersham Biosciences, Tokyo, Japan), we performed overnight hybridisation at $65^{\circ} \mathrm{C}$ with the probe pl3E-11, as described previously. ${ }^{8}$ We also used probe pMAl3 to identify people with a deletion of the pl3E-11 recognition site and with hybrid repeats that consisted of clusters of type 4 and type $10 \mathrm{KpnI}$ units. pMA13 is a $1.3 \mathrm{~kb}$ StuI digested fragment within the KpnI unit. We scanned the hybridised membranes and stored the image data for densitometric analysis. We estimated the intensity of each fragment with densitometry and BAS2500 (Fuji Photo Film, Tokyo, Japan). For people with somatic mosaicism, we estimated the proportion of cells with a small EcoRI fragment by comparing the labelled intensity with the expected intensity. 
We used the BglII/BlnI dosage test with the probe pl3E-11, as reported previously, to detect the interchromosomal translocation. ${ }^{22}$ This method characterises the first KpnI repeat as a $B \ln \mathrm{I}$ resistant $4.0 \mathrm{~kb}$ (chromosome type 4q) fragment or a $B \ln \mathrm{I}$ sensitive $1.8 \mathrm{~kb}$ (chromosome type 10q) fragment. We calculated the intensity ratio of the two bands and classified all people in accordance with the number of chromosomes with BlnI resistant (type 4q) KpnI units: nullsomy ( $\mathrm{N}$ : two type 10q repeats on chromosome 4), monosomy (M: one type $10 \mathrm{q}$ repeat on chromosome 4), disomy (D: standard), trisomy ( $\mathrm{T}$ : one type $4 \mathrm{q}$ repeat on chromosome 10), or quatrosomy (Q: two type $4 \mathrm{q}$ repeats on chromosome 10).

\section{RESULTS}

All 85 unrelated patients had clinical symptoms consistent with FSHD and a small EcoRI fragment of the $4 \mathrm{q} 35$ region $<35 \mathrm{~kb}$. The fragment sizes were 10-27 (mean 17.5) kb.

In 35/85 (41\%) families, only the proband had a small $B \ln \mathrm{I}$ resistant EcoRI fragment; these cases were suggested to be the result of de novo mutations (fig 1). Nineteen patients were men and 16 women. The size of the small EcoRI fragment varied from 10 to 27 (mean 15.2) kb. All but one proband had four EcoRI fragments (derived from both chromosomes 4 and 10). One patient had five EcoRI fragments that included a faint $10 \mathrm{~kb}$ fragment, and this was suggested to be somatic mosaicism. The BglII/BlnI dosage test showed that $5 / 29(17 \%)$ of the de novo probands, including one patient with mosaicism, had one type 4 repeat on chromosome 10 (trisomy), and others had a standard disomic pattern (data not shown).

The remaining 50 patients were familial cases; one parent had a small EcoRI fragment of the same size as that of the proband. Twenty-three patients inherited a small EcoRI fragment from their father and 27 from their mother.

Surprisingly, $26(52 \%)$ of the parents (11 fathers and 15 mothers) with a small EcoRI fragment had no clinical symptoms (fig 1). Overall, 17/85 (20\%) of families had a parent with somatic mosaicism. The age range of parents with a small EcoRI fragment who were unaffected by the disease was 40-75 (mean 57.4) years at the time of examination, and the size of the short EcoRI fragment varied from 10 to 26 (mean 19.3) kb. The other parents who had a small EcoRI fragment (12 fathers and 12 mothers) had

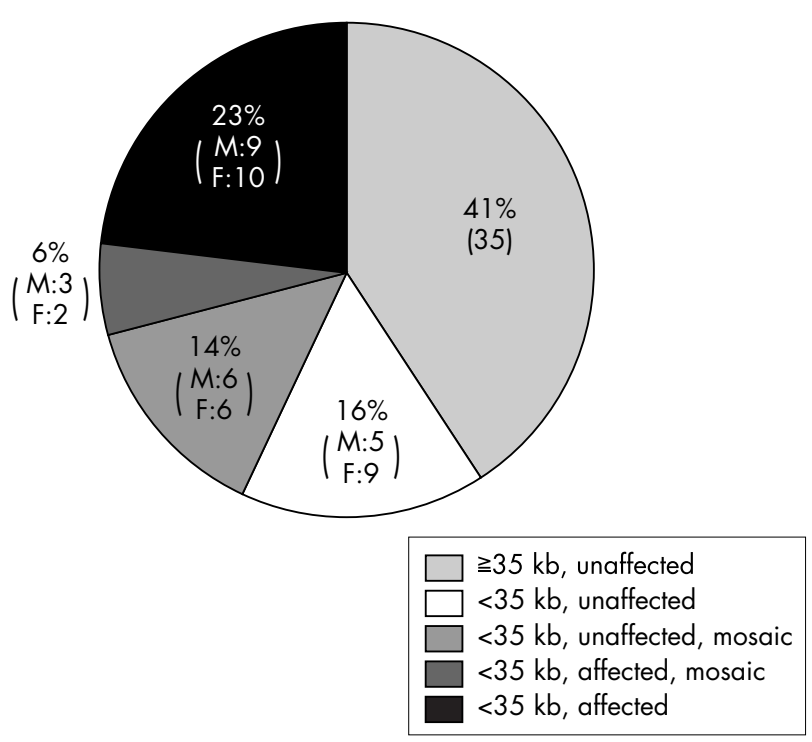

Figure 1 Results of southern blotting analysis and clinical symptoms of 85 families of patients with FSHDIA. M, male; F, female. clinical symptoms consistent with FSHD. The age range of parents with symptoms of FSHD was 38-67 (mean 52.8) years, and the small fragment sizes ranged from 12 to 25 (mean 18.7) kb. Interestingly, no correlation was seen between the development of clinical symptoms and the size of the small EcoRI fragment (fig 2). One mother who had a $25 \mathrm{~kb} E c o$ RI fragment had weakness in the shoulders, but no muscle weakness was observed in one father with a $14 \mathrm{~kb}$ fragment.

Southern blotting analysis showed that $17 / 50$ carrier parents with a deleted allele had five EcoRI fragments that included a fainter, small EcoRI fragment (fig 3). Double digestion with EcoRI and BlnI showed one more BlnI resistant fragment than was expected from the $B g l \mathrm{II} / B \ln \mathrm{I}$ dosage test (data not shown). Densitometrical analysis confirmed that the radiolabelling intensity of these small EcoRI fragments was fainter than expected and varied from $15 \%$ to $90 \%$. These results suggest that $17 / 50$ (34\%) of parents with a small EcoRI fragment had somatic mosaicism of the $4 \mathrm{q} 35$ region and two cell populations with different combinations of EcoRI fragments. Five parents with mosaicism (three fathers and two mothers) had clinical symptoms consistent with FSHD, but 12 parents with mosaicism (six fathers and six mothers) were unaffected (fig 1). The size and intensity of a small EcoRI fragment were variable and did not correlate with the clinical features of the disease. A man with mosaicism with a $20 \mathrm{~kb}$ fragment was affected, while a man with a $10 \mathrm{~kb}$ fragment with mosaicism was asymptomatic (fig 2). In addition, a man with a $17 \mathrm{~kb}$ fragment in $90 \%$ of cells was unaffected, but women with the same sized fragment in $46 \%$ and $52 \%$ of cells had clinical symptoms consistent with FSHD (data not shown).

The interchromosomal translocation between $4 \mathrm{q} 35$ and 10q26 was seen in 4/13 (31\%) people with somatic mosaicism. Three parents (one father and two mothers) had three type 4 repeats (trisomy), and one father had monosomy of a type 4 repeat (data not shown).

\section{DISCUSSION}

Facioscapulohumeral muscular dystrophy is a dominantly inherited common muscular dystrophy with a high occurrence of new mutations. ${ }^{1} 10112324$ Most patients with FSHD had a deletion of tandem repeated $3.3 \mathrm{~kb} K p n \mathrm{I}$ units on chromosome $4 \mathrm{q} 35$, but the deletion mechanism of the repeat units is not known. Genetic analysis of 85 unrelated Japanese patients with FSHDIA and both parents of each patient by southern blotting analysis found that $41 \%$ of cases were the result of de novo mutations. A high proportion of de novo mutations may be caused by the specific structure of the region associated with FSHD on chromosome 4.

A possible consideration with respect to the shortened repeats is interchromosomal translocation between the subtelomeric region of chromosomes 4 and 10, which is observed in $20-30 \%$ of the healthy population. ${ }^{14}{ }^{17}$ Frequently observed recombination implies a role for deletion of the $4 \mathrm{q} 35$ region; however, the ratio of translocation is similar between healthy people and patients with the disease. ${ }^{17}$ The translocation ratio in the 35 patients with de novo mutations in our study was not significantly different from that reported previously in healthy people. ${ }^{17}$ Further studies are needed to elucidate the exact role of interchromosomal translocation for the deletion of repeated units on $4 \mathrm{q} 35$.

Another possible cause is somatic mosaicism. Somatic mosaicism of the $4 \mathrm{q} 35$ region was seen in $15-20 \%$ of the healthy parents of patients with FSHD. ${ }^{1023-25}$ Van der Maarel et al reported that the patient or an asymptomatic parent had somatic mosaicism in $40 \%$ of families with de novo cases of FSHD. ${ }^{21}$ On the other hand, only $3 \%$ of random blood donors have somatic mosaicism. ${ }^{16}$ In our study, $17 / 50$ (34\%) parents 


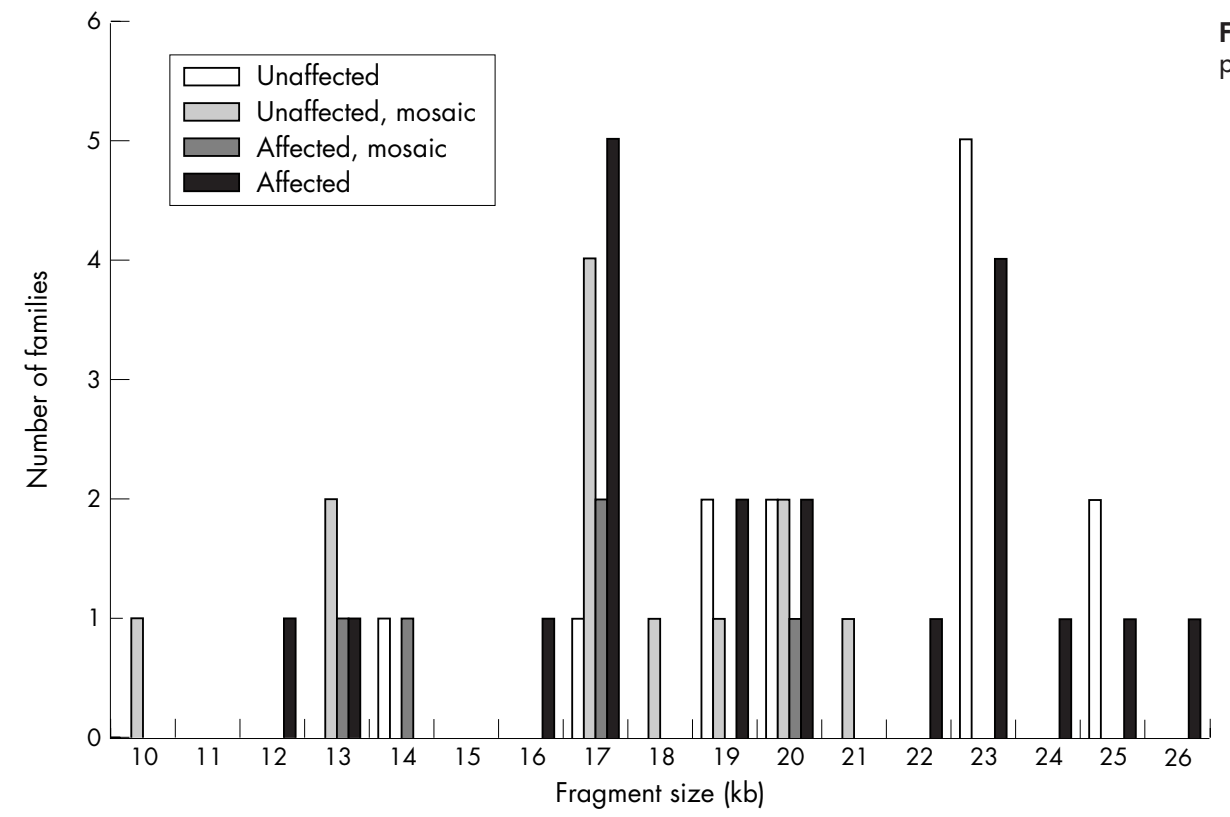

with a deleted allele had somatic mosaicism of the $4 \mathrm{q} 35$ region, and 17/85 (20\%) of patients with FSHDlA inherited a small EcoRI fragment from parents with mosaicism. These results suggest that somatic mosaicism is one of the major factors in the development of FSHDIA. A previous study showed that $46 \%$ of people with mosaicism had one or more $B \ln \mathrm{I}$ resistant units on chromosome 10; that is nearly fivefold more frequent than in healthy people. ${ }^{21}$ In the present study,
Figure 2 EcoRl fragment size of parents with a deleted allele. however, 3/13 (23\%) of parents with mosaicism had type 4q $B \ln \mathrm{I}$ resistant units on chromosome 10; this proportion was similar to that in healthy people. ${ }^{17}$

In the people with mosaicism, the size and intensity of a small EcoRI fragment were variable and did not correlate with the clinical features of the disease. This result may not be surprising, however, because somatic mosaicism occurs in the early embryonic stage, and the percentage of cells with
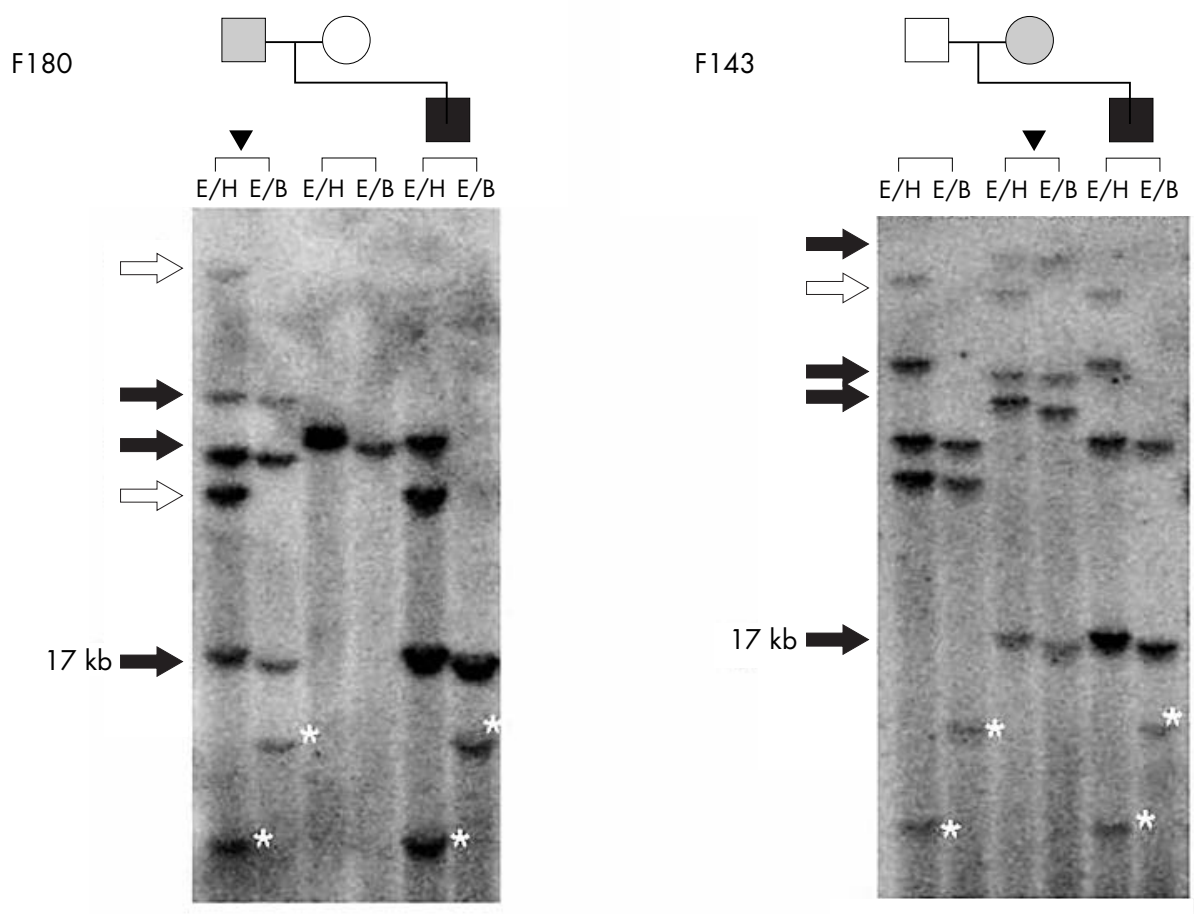

Figure 3 Southern blotting analysis of two families with a proband with FSHDIA and a parent with somatic mosaicism. DNA was digested by EcoRI/ HindllI (E/H) and EcoRI/Blnl (E/B) and separated by PFGE. The father in F180 (arrowhead) had three Blnl resistant EcoRI fragments (black arrows) that included a faint small (17 kb) EcoRl fragment. The affected son inherited the small fragment from his father. Fragments derived from chromosome 10 are shown with white arrows. The mother in F143 (arrowhead) had four BInl resistant EcoRI fragments (black arrows) that included a faint $17 \mathrm{~kb}$ fragment and one Blnl sensitive EcoRl fragment (white arrow). This mother was confirmed to have one type 4 repeat on chromosome 10 (trisomy) by the $\mathrm{Bg}$ ll/ $/ \mathrm{hlnl}$ dosage test. The affected son carried this $17 \mathrm{~kb}$ fragment. Alleles from chromosome $\mathrm{Y}$ are marked with asterisks. 
deleted alleles will vary between tissues. In our study, no significant difference was seen between the sexes in the clinical symptoms in parents with mosaicism, although asymptomatic female carriers of mosaicism have been reported as predominant. ${ }^{102125}$

When we consider the penetrance of FSHD, our findings are important. Despite the clinical heterogeneity, even in the same family, patients with FSHD usually become symptomatic in the second decade of life. Penetrance increases in an age dependent manner and has been estimated to be $<5 \%$ for children aged $0-4$ years, $21 \%$ for those aged 5-9 years, $58 \%$ for those aged $10-14$ years, $86 \%$ for those aged $15-19$ years, and $95 \%$ for those aged $\geqslant 20$ years. ${ }^{26}$ Another study showed that non-penetrance at the age of 60 years has been estimated as $2-5 \%{ }^{27}$ From these studies, FSHD was suggested to be a highly penetrant disease. Our retrospective study, however, showed that penetrance was low, being estimated at 59\% (excluding somatic mosaicism) and $48 \%$ (including somatic mosaicism). The number of mothers without mosaicism who were unaffected by the disease was higher than the number of fathers; however, no significant differences between sexes were seen in the numbers of affected parents and of parents with mosaicism. The size of small EcoRI fragments of unaffected parents was variable; the smallest fragment was $14 \mathrm{~kb}$. This fragment was estimated to contain only two KpnI repeated units (D4Z4), which generally causes severe phenotypes from childhood. Further clinical follow up studies of parents with a small EcoRI fragment who are unaffected by FSHD are needed. Penetrance, however, seems to be lower than previously reported. Even in random blood donors, 3-6\% of people have FSHD sized type 4 repeat arrays. $^{8}{ }^{1628}$ The existence of asymptomatic people with a small EcoRI fragment strongly suggests the involvement of additional unknown factors in the development of clinical symptoms. Position effect variegation, which induces allele specific transcriptional repression of genes located centromerically, has been proposed as the molecular mechanism of FSHD. Recently, unexpected gene expression that was related inversely to the number of repeat units was reported in the muscles of patients with FSHD. ${ }^{29}$ In addition, one of the two variants of the $4 \mathrm{q}$ subtelomere was reported to be associated uniquely with patients with FSHD. ${ }^{30}$ Additional studies are needed to clarify the molecular pathomechanism of this complicated disease.

\section{ACKNOWLEDGEMENTS}

This work was supported by Grants-in-Aid for Research on Psychiatric and Neurological Diseases and Mental Health from the Ministry of Health, Labour and Welfare and Ichiro Kanehara Memorial Foundation, Japan.

\section{Authors' affiliations}

K Goto, I Nishino, Y K Hayashi, Department of Neuromuscular Research, National Institute of Neuroscience, National Center of Neurology and Psychiatry (NCNP), Tokyo, Japan

Correspondence to: Dr Y K Hayashi, Department of Neuromuscular Research, National Institute of Neuroscience, NCNP, 4-1-1 OgawaHigashi, Kodaira, Tokyo 187-8502, Japan; hayasi_y@ncnp.go.jp

Received 29 March 2003

Accepted 16 June 2003

\section{REFERENCES}

1 Lunt PW, Harper PS. Genetic counselling in facioscapulohumeral muscular dystrophy. J Med Genet 1991;28:655-64.

2 Wijmenga C, Frants RR, Brouwer OF, Moerer P, Weber JL, Padberg GW. Location of facioscapulohumeral muscular dystrophy gene on chromosome 4. Lancet 1990;336:651-3.

3 Sarfarazi M, Wijmenga C, Upadhyaya M, Weiffenbach B, Hyser C, Mathews K, Murray JC, Gilbert J, Pericak-Vance M, Lunt P, Frants RR,
Jacobsen S, Harper PS, Padberg GW. Regional mapping of facioscapulohumeral muscular dystrophy gene on $4 \mathrm{q} 35$ : combined analysis of an international consortium. Am J Hum Genet 1992;51:396-403.

4 Upadhyaya M, Lunt P, Sarfarazi M, Broadhead W, Farnham J, Harper PS. The mapping of chromosome $4 \mathrm{q}$ markers in relation to facioscapulohumeral muscular dystrophy (FSHD). Am J Hum Genet 1992;51:404-10.

5 Wijmenga C, Hewitt JE, Sandkuijl LA, Clark LN, Wright TJ, Dauwerse JG Gruter A-M, Hofker MH, Moerer P, Williamson R, Van Ommen GJB, Padberg GW, Frants RR. Chromosome 4q DNA rearrangements associated with facioscapulohumeral muscular dystrophy. Nature Genet 1992;2:26-30.

6 van Deutekom JC, Wiijmenga C, van Tienhoven EA, Gruter AM, Hewitt JE, Padberg GW, van Ommen GJ, Hofker MH, Frants RR. FSHD associated DNA rearrangements are due to deletions of integral copies of a $3.2 \mathrm{~kb}$ tandemly repeated unit. Hum Mol Genet 1993;2:2037-42.

7 Gilbert JR, Stajich JM, Wall S, Carter SC, Qiu H, Vance JM, Stewart CS, Speer MC, Pufky J, Yamaoka LH, Rozear M, Samson F, Fardeau M, Roses AD, Pericak-Vance MA. Evidence for heterogeneity in facioscapulohumeral muscular dystrophy (FSHD). Am J Hum Genet 1993;53:401-8.

8 Goto K, Lee JH, Matsuda C, Hirabayashi K, Kojo T, Nakamura A, Mitsunaga Y, Furukawa T, Sahashi K, Arahata K. DNA rearrangements in Japanese facioscapulohumeral muscular dystrophy patients: clinical correlations. Neuromuscul Disord 1995;5:201-8.

9 Lunt PW, Jardine PE, Koch MC, Maynard J, Osborn M, Williams M Harper PS, Upadhyaya M. Correlation between fragment size at D4F104S1 and age at onset or at wheelchair use, with a possible generational effect, accounts for much phenotypic variation in 4q35-facioscapulohumeral muscular dystrophy (FSHD). Hum Mol Genet 1995;4:951-8.

10 Zatz M, Marie SK, Passos-Bueno MR, Vainzof M, Campiotto S, Cerqueira A, Wijmenga $C$, Padberg G, Frants R. High proportion of new mutations and possible anticipation in Brazilian facioscapulohumeral muscular dystrophy families. Am J Hum Genet 1995;56:99-105.

11 Tawil R, Forrester J, Griggs RC, Mendell J, Kissel J, McDermott M, King W, Weiffenbach B, Figlewicz D. Evidence for anticipation and association of deletion size with severity in facioscapulohumeral muscular dystrophy. The FSH-DY Group. Ann Neurol 1996;39:744-8.

12 Funakoshi M, Goto K, Arahata K. Epilepsy and mental retardation in a subset of early onset $4 \mathrm{q} 35$-facioscapulohumeral muscular dystrophy. Neurology 1998:50:1791-4.

13 Deidda G, Cacurri S, Piazzo N, Felicetti L. Direct detection of 4 q35 rearrangements implicated in facioscapulohumeral muscular dystrophy (FSHD). J Med Genet 1996;33:361-5.

14 Van Deutekom JC, Bakker E, Lemmers RJ, van der Wielen MJ, Bik E, Hofker MH, Padberg GW, Frants RR. Evidence for subtelomeric exchange of $3.3 \mathrm{~kb}$ tandemly repeated units between chromosomes $4 \mathrm{q} 35$ and 10q26: implications for genetic counselling and etiology of FSHD1. Hum Mol Genet 1996:5:1997-2003.

15 Lemmers RJ, van der Maarel SM, van Deutekom JC, van der Wielen MJ, Deidda G, Dauwerse HG, Hewitt J, Hofker M, Bakker E, Padberg GW, Frants RR. Inter- and intrachromosomal sub-telomeric rearrangements on 4q35: implications for facioscapulohumeral muscular dystrophy (FSHD) aetiology and diagnosis. Hum Mol Genet 1998;7:1207-14.

16 van Overveld PG, Lemmers RJ, Deidda G, Sandkuigl L, Padberg GW, Frants RR, van der Maarel SM. Interchromosomal repeat array interactions between chromosomes 4 and 10: a model for subtelomeric plasticity. Hum Mol Genet 2000;9:2879-84.

17 van Overveld PG, Lemmers RJ, Deidda G, Sandkuijl L, Padberg GW, Frants RR, van der Maarel SM. Chromosome $4 \mathrm{q} ; 10 \mathrm{q}$ translocations; Comparison with different ethnic populations and FSHD patients. BMC Neurol 2002;2:7.

18 Griggs RC, Tawil R, Storvick D, Mendell JR, Altherr MR. Genetics of facioscapulohumeral muscular dystrophy: new mutations in sporadic cases. Neurology 1993;43:2369-72

19 Weiffenbach B, Dubois J, Storvick D, Tawil R, Jacobsen SJ, Gilbert J, Wijmenga C, Mendell JR, Winokur S, Altherr MR, Schultz P, Olandt S, Frants RR, Pericak-Vance M, Griggs RC. Mapping the facioscapulohumeral muscular dystrophy gene is complicated by chromosome $4 \mathrm{q} 35$ recombination events. Nature Genet 1993;4:165-9.

20 Galluzzi G, Deidda G, Cacurri S, Colantoni L, Piazzo N, Vigneti E, Ricci E, Servidei S, Merico B, Pachi A, Brambati B, Mangiola F, Tonali P, Felicetti L. Molecular analysis of $4 \mathrm{q} 35$ rearrangements in fascioscapulohumeral muscular dystrophy (FSHD): application to family studies for a correct genetic advice and a reliable prenatal diagnosis of the disease. Neuromuscul Disord 1999;9:190-8.

21 van der Maarel SM, Deidda G, Lemmers RJ, van Overveld PG, van der Wielen M, Hewitt JE, Sandkuijl L, Bakker B, van Ommen GJ, Padberg GW, Frants RR. De novo facioscapulohumeral muscular dystrophy: frequent somatic mosaicism, sex-dependent phenotype, and the role of mitotic transchromosomal repeat interaction between chromosomes 4 and 10 . Am J Hum Genet 2000;66:26-35.

22 van der Maarel SM, Deidda G, Lemmers RJ, Bakker E, van der Wielen MJ, Sandkuiil L, Hewitt JE, Padberg GW, Frants RR. A new dosage test for subtelomeric 4;10 translocations improves conventional diagnosis of facioscapulohumeral muscular dystrophy (FSHD). J Med Genet 1999;36:823-8.

23 Padberg GW, Frants RR, Brouwer OF, Wijmenga C, Bakker E, Sandkuijl LA. Facioscapulohumeral muscular dystrophy in the Dutch population. Muscle Nerve 1995;2:S81-4. 
24 Upadhyaya M, Maynard J, Osborn M, Jardine P, Harper PS, Lunt P. Germinal mosaicism in facioscapulohumeral muscular dystrophy (FSHD). Muscle Nerve 1995;2:S45-9.

25 Kohler J, Rupilius B, Otto M, Bathke K, Koch MC. Germline mosaicism in $4 \mathrm{q} 35$ facioscapulohumeral muscular dystrophy (FSHD1A) occurring predominantly in oogenesis. Hum Genet 1996;98:485-90.

26 Lunt PW, Compston DA, Harper PS. Estimation of age dependent penetrance in facioscapulohumeral muscular dystrophy by minimizing ascertainment bias. J Med Genet 1989;26:755-60.

27 Padberg G. Facioscapulofumeral disease [MD Thesis]. Leiden: Leiden University, 1982.
28 Nakagawa M, Matsuzaki T, Higuchi I, Fukunaga $H$, Inui T, Nagamitsu S, Yamada H, Arimura K, Osame M. Facioscapulohumeral muscular dystrophy: clinical diversity and genetic abnormalities in Japanese patients. Intern Med 1997; 36:333-9.

29 Gabellini D, Green MR, Tupler R. Inappropriate gene activation in FSHD: a repressor complex binds a chromosomal repeat deleted in dystrophic muscle. Cell 2002;110:339-48.

30 Lemmers RJ, de Kievit P, Sandkuiil L, Padberg GW, van Ommen GJ, Frants RR, van der Maarel SM. Facioscapulohumeral muscular dystrophy is uniquely associated with one of the two variants of the $4 \mathrm{q}$ subtelomere. Nature Genet 2002;32:235-6. 